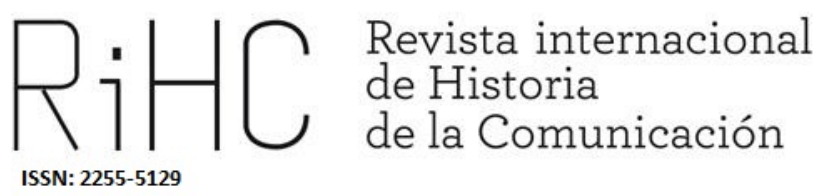

\title{
CAMINOS DE LA HISTORIA DE LA TELEVISIÓN DIGITAL EN RIO GRANDE DO NORTE
}

Historical paths of Digital Television in Rio Grande do Norte

DOI: http://dx.doi.org/10.12795/RiHC.2019.i13.06

Recibido: $17 / 10 / 2019$

Aceptado: $16 / 12 / 2019$

Publicado: $15 / 12 / 2019$

Valquiria Aparecida Passos Kneipp

ORCID (iD 0000-0001-5522-6961

Universidade Federal do Rio Grande do Norte, Brasil

valquiriakneipp@yahoo.com.br

Luciana Salviano Marques da Silva

ORCID (iD) 0000-0002-3932-4761

Universidade Federal do Rio Grande do Norte, Brasil

luciana.salvianoms@gmail.com

Como citar este artículo: PASSOS KNEIPP, Valquiria y SALVIANO MARQUES DA SIVLA, Luciana (2019): "Caminos de la historia de la televisión digital en Rio Grande do Norte", en Revista Internacional de Historia de la Comunicación (13), ISSN 2255 -5129, pp. 91-106. 
Resumen: Este texto es parte del proyecto desarrollado en la Universidad Federal de Rio Grande do Norte en los años 2017 y 2018. El objetivo fue identificar cómo se dio la trayectoria de la televisión digital en Rio Grande do Norte. Entre los objetivos se buscó mapear el processo de desarrollo de la tecnología digital en las emissoras de televisión, investigar la trayectoria de migración de las emissoras analógicas a digitales, comprender los motivos del relativo retraso tecnológico de las emissoras regionales y la actual crisis de los medios globales. Para la realización del mapeo fueron empleadas y combinadas la investigación documental, en los periódicos de la ciudad, entrevistas con los profesionales, realizadas a partir de algunos preceptos de la historia oral, como la grabación en video. Se buscó personas en todas las emissoras, para en un primer momento identificar una cronología de la implantación de la televisión digital en el Estado. Las entrevistas grabadas fueron transcritas para ser utilizadas como fuente de información y serán divulgadas a través de una publicación para la referencia de investigadores, estudiantes y la sociedad en general. El Estado de Rio Grande do Norte tuvo su primera emissora de televisión en 1972, la TVU fue implantada con la primera programación local en el Estado. Antes algunas retransmisoras fueron instaladas desde el final de la década de 1950, primero por toda región sudeste y sur de forma gradual. En el noreste el processo fue más largo. Por eso, se hace necesario investigar y entender cómo se dio el processo de digitalización de estos medios tan importante en la vida de las personas. Hay un espacio en la historia y en la memoria de la sociedad Potiguar para pensar y problematizar como ocurrió el desarrollo de las emissoras en el RN.

Palabras clave: Televisión, Río Grande do Norte, Historia Oral, Trayectoria, Digital.

\begin{abstract}
This text is part of the project developed at the Federal University of Rio Grande do Norte, in the years 2017 and 2018. The objective was to identify how the digital television trajectory occurred in Rio Grande do Norte. The objectives were to map the process of developing digital technology in television stations, to investigate the migration path from analogue to digital broadcasters, to understand the reasons for the relative technological backwardness of regional broadcasters and the current global media crisis. In order to carry out the mapping, documentary research was used and combined in the city newspapers, interviews with professionals, based on some precepts of oral history, such as video recording. People were sought in all the stations, in order to first identify a chronology of the implantation of the digital television in the State. The work followed with the formation of some networks of interviewees, which were grouped by period and by broadcaster. The recorded interviews were transcribed to be used as a source of information and will be disseminated through a website (memoriadatvpotiguar) and will also compose a publication for the reference of researchers, students and society in general. The State of Rio Grande do Norte had its first television station in 1972, TVU was implemented with the first local programming in the State. Some retransmitters have been installed since the late 1950s, primarily throughout the Southeast and South gradually. In the northeast the process was more time consuming. Therefore, it is necessary to investigate and understand how the process of digitization of this important media in people's lives took place. There is a space in the history and memory of the Potiguar society to think about and problematize how the development of the stations in the RN occurred.
\end{abstract}

Keywords: Television, Rio Grande do Norte, Oral History, Trajectory, Digital. 


\section{Marco teórico}

Este artigo é resultado do projeto de pesquisa ${ }^{1}$, que deu continuidade a uma pesquisa inicial desenvolvida de 2014 até 2016, intitulada "Trajetória da TV no RN". Visto que no primeiro projeto de pesquisa foi realizado um levantamento da trajetória das emissoras de televisão no Estado do Rio Grande do Norte, desde a chegada da TV no Brasil em 1950 até os dias atuais. A referida pesquisa contou com uma bolsa de iniciação científica $^{2}$ custeada pela Universidade Federal do Rio Grande do Norte, por meio do Conselho Nacional de Desenvolvimento Científico e Tecnológico, CNPq. A primeira etapa resultou na organização de um livro com textos sobre a trajetória das quatro primeiras emissoras do Rio Grande do Norte, e também com participação de pesquisadores de todo Brasil sobre temas que englobam a história da mídia, intitulado: "Trajetória da Televisão no Rio Grande do Norte - a fase analógica" - Volume 1. O livro encontra-se disponível no repositório da Editora da UFRN (https://repositorio.ufrn.br/jspui/bitstream/123456789/24528/1/Trajetoria_da_TV_no _RN_a_fase_analogica.pdf).

Para o segundo projeto de pesquisa pretendeu-se dar continuidade a primeira etapa e, desta vez, investigar as emissoras de televisão na era digital, com o objetivo de compreender como se deu o processo de implantação e desenvolvimento desta inovação nas emissoras de televisão do Estado do Rio Grande do Norte.

No Brasil, o início do processo de digitalização da televisão se deu no dia 02 de dezembro de 2007 na cidade de São Paulo. A finalização deste processo, com o desligamento total do sinal analógico, de acordo com o Ministério das Comunicações está prevista para 2023.

O Estado do Rio Grande do Norte teve sua primeira emissora de televisão nos anos de 1970, depois de 22 anos da chegada da televisão no Brasil. Em 1972, a TV Universitária (TVU) foi implantada como a primeira, com programação local no Estado. Antes dela, apenas algumas retransmissoras foram instaladas desde o final da década de 1950. 0 desenvolvimento da televisão no país se intensificou primeiramente, por toda região sudeste e sul de forma gradual. No nordeste o processo foi mais demorado. Por isso, depois de mais de 40 anos se faz necessário investigar e entender, além de dar continuidade à pesquisa de como se deu o processo de implantação desta mídia tão importante na vida das pessoas. Existe um espaço na história e na memória da sociedade Potiguar para se pensar e problematizar como ocorreu o desenvolvimento das emissoras no Rio Grande do Norte. No primeiro projeto de pesquisa, aprofundaram-se nas primeiras cinco emissoras (TVU, InterTV, TV Ponta Negra, TV Tropical e Band Natal) existentes no Estado, que foram instaladas no período analógico. Agora se pretendeu

\footnotetext{
${ }^{1}$ Una versión previa del texto fue presentado al XVI Congreso de AsHisCom de Santiago, en 2019.

${ }^{2}$ A aluna de graduação Luciana Salviano Marques da Silva foi bolsista no projeto.
} 
avançar para a era digital, e mostrar como está o processo de digitalização das emissoras, e, ainda, identificar as novas formas de televisão existentes, bem como as emissoras legislativas e as transmissões via internet. A Universidade Federal do Rio Grande do Norte mostrou-se ser um local adequado para abrigar a pesquisa. Estamos em plena era digital, onde as emissoras estão passando por um novo processo de mudança na transmissão de sinal, e esta história precisa ser contada, registrada e publicada, como uma forma de manter a memória e valorizar a trajetória e desenvlvimento do veículo. Por meio da pesquisa pretende-se organizar uma nova publicação para dar continuidade à primeira.

Dentre os objetivos da pesquisa está a identificação da trajetória da televisão digital no Rio Grande do Norte desde a digitalização da primeira emissora. Além disso, objetiva-se também mapear o processo de desenvolvimento da tecnologia digital nas emissoras de televisão; investigar a trajetória de migração das emissoras analógicas para digitais no $\mathrm{RN}$, no contexto do país e da região nordeste; compreender os motivos do relativo atraso tecnológico das emissoras regionais e a atual crise da mídia global.

Esta pesquisa faz-se necessária como uma forma de investigar, registrar e divulgar para a sociedade acadêmica todo o processo pelo qual passou e vem passando a televisão Potiguar, no seu passado, como subsídio para o entendimento do estágio atual. No Rio Grande do Norte existem cinco emissoras comerciais abertas em funcionamento na cidade de Natal. Sendo importante destacar que todas elas estão transmitindo com sinal digital (afiliadas das Redes Record, Bandeirantes, Globo, TV Brasil e SBT). Além das já citadas, existem outras 16 emissoras entre TVs legislativas, comunitárias, dentre outras. O estágio de midiatização da sociedade vem impondo um novo ritmo às mídias, e por esta razão a televisão passa por mais um processo de mudança, adaptação e hibridação com a internet, na busca pela audiência. Esse novo cenário de convergência, segundo Jenkins (2009) propõe uma narrativa transmídia, com o processo crescente de participação do espectador, que deixa de ser apenas um agente passivo e receptor. Desta forma a televisão, a partir do processo de digitalização passou a ter novas configurações, tanto no processo de transmissão quanto no processo de produção de conteúdos. E, portanto, dar continuidade ao processo de investigação que busca compreender como a televisão no Rio Grande do Norte atravessou toda essa trajetória torna-se fundamental para o campo da pesquisa em comunicação, principalmente como forma de contribuir para a história da mídia regional. 


\section{A Televisão no cenário de convergência digital}

Para Cannito (2010) a pesquisa e a inovação são os novos paradigmas para televisão digital, diante da revolução tecnológica em curso. O autor se refere ao momento histórico pelo qual a televisão brasileira está pasando, com a mudança do sinal analógico para o digital. Ele ressalta ainda que passado o momento de transformações tecnológicas, "o diferencial estará nos conteúdos" (251). De acordo com o pesquisador, o conteúdo é fundamental porque, "abarca muito mais que o próprio mundo digital. A cultura digital é multiplataforma por definição, daí as mídias não digitais também serem importantes" (CANNITO, 2010: 251).

A convergência conceituada por Jenkins (2009) está diretamente ligada ao processo de digitalização da televisão no Brasil. Para o autor, a palavra define mudanças tecnológicas, industriais, culturais e sociais da maneira como as mídias circulam na cultura. "Algumas das ideias expressas por este termo incluem fluxo de conteúdos através de várias plataformas de mídia, a coperação entre multiplas indústrias midiáticas, a busca de novas estruturas de financiamento das mídias" (Jenkins, 2009: 377). Para ele a convergência pode ser alternativa, corporativa, cultural e tecnológica. De forma que cada uma delas apresenta algunas peculiaridades. Na convergência alternativa, por exemplo, "fluxo informacional e às vezes não autorizado de conteúdos de mídia quando se torna fácil aos consumidores arquivar, comentar os conteúdos, apropriar-se deles e colocá-los de volta em circulação" (377), já na corporativa isso não ocorre devido ao "fluxo comercialmente direcionado de conteúdos de mídia". As aproximações que estão mais voltadas para o objeto desta pesquisa são a convergência tecnológica que é a "combinação de funções dentro do mesmo aparelho tecnológico" (377), que foi o que a digitalização da televisão acabou propiciando para o telespectador; e a convergência cultural, que trata da ação de todo este processo na sociedade porque propõe uma "mudança na lógica pela qual a cultura opera, com ênfase no fluxo de conteúdos pelos canais de mídia" (377).

\section{A oralidade como método de pesquisa}

Para o desenvolvimento desta pesquisa, selecionou-se um instrumental metodológico contando com várias técnicas e estratégias. Desde a pesquisa bibliográfica, pesquisa documental, nos jornais da cidade, em publicações, bem como entrevistas com os profissionais da área, que foram realizadas a partir de alguns preceitos da história oral, como a gravação em vídeo para a formação de um banco de imagens, posteriormente. Inicialmente foram selecionadas estas ferramentas metodológicas, no entanto durante 
o desenvolvimento do projeto outras práticas foram incorporadas ou substituídas, de acordo com a necessidade do mesmo. Além da busca por documentos, as entrevistas identificaram pessoas em todas as emissoras existentes na cidade de Natal, para em um primeiro momento organizar uma cronologia da implantação da televisão digital no estado do Rio Grande do Norte.

O uso da história oral como metodologia se justifica no desenvolvimento desta pesquisa por se tratar de um fenômeno contemporâneo em pleno desenvolvimento, e de acordo com José Carlos Sebe Bom Meihy "a História oral é um recurso moderno usado para a elaboração de documentos, arquivamento de estudos referentes à experiência social de pessoas e grupos. Ela é sempre uma história do "tempo presente" e também reconhecida como "história viva"”" (2005: 17). A partir dos dois gêneros propostos pelo autor, a saber: história oral de vida e história oral temática, esta pesquisa enquadrou-se em história oral temática porque se buscou entrevistados, das diversas emissoras do estado do Rio Grande do Norte para relatar a experiência e o processo de implantação da televisão digital. A partir disso, iniciou-se a formação da colônia, ou seja, da escolha dos entrevistados, que teve como objetivo identificar pessoas em todas as emissoras para a sua formação.

O conceito de colônia está relacionado exclusivamente ao fundamento da identidade cultural do grupo; são os elementos amplos que marcam a identidade geral dos seguimentos dispostos à análise. Classe social, gênero e etnia são pontos básicos do conceito de colônia (José Carlos Sebe Bom Meihy, 2005: 177).

Desta forma, a Colônia foi formada com integrantes das cinco emissoras selecionadas. Neste artigo, apresentamos, conforme o quadro 1, as entrevistas com alguns dos profissionais de três das cinco emissoras pesquisadas. No momento da escrita deste trabalho as demais entrevistas ainda estavam sendo realizadas e outras em fase de transcrição.

\section{Quadro 1: Colônia dos primeiros entrevistados}

\begin{tabular}{|l|l|}
\hline $\begin{array}{l}\text { Colônia dos profissionais de } \\
\text { Comunicação da televisão do Rio } \\
\text { Grande Norte }\end{array}$ & Profissionais da TV Ponta Negra (SBT) \\
\hline & Profissionais da TV Tropical (Record) \\
\hline Profissionais da TVU (TV Brasil) \\
\hline Profissionais da Band Natal (Bandeirantes) \\
\hline
\end{tabular}

(Elaborado pelas autoras)

A partir da definição da colônia dos entrevistados começou-se a identificar os entrevistados nas respectivas emissoras para a formação da rede, que vem a ser uma subdivisão da colônia, funcionando assim, como um indicativo de modo a articular as 
entrevistas. "A colônia é sempre um grupo amplo, da qual a rede é a espécie ou parte menor que possa caber nos limites de um projeto plausível de ser executado" (José Carlos Sebe Bom Meihy, 2005: 177). Com isso, começou-se a elaborar a rede como uma subdivisão da colônia a fim de "estabelecer parâmetros para decidir sobre quem se deve e quem não deve entrevistar" (José Carlos Sebe Bom Meihy, 2005; 177). Os cortes realizados para chegar à escolha final dos entrevistados basearam-se na disponibilidade que os profissionais demonstraram para conceder as entrevistas, conforme pode ser visto no quadro 2, com o primeiro grupo entrevistado e a formação de suas respectivas redes.

\section{Quadro 2-Redes formadas pelas emissoras e os entrevistados}

\begin{tabular}{|l|l|l|}
\hline Redes & Entrevistados & Cargos \\
\hline 1-) InterTV Cabugi & $\begin{array}{l}\text { Filipo Cunha } \\
\text { Luiz Veiga } \\
\text { Diana Barreto }\end{array}$ & $\begin{array}{l}\text { Chefe de Reportagem } \\
\text { Diretor de Jornalismo } \\
\text { Produtora de Jornalismo }\end{array}$ \\
\hline 2-) TVU & lano Maia & Chefia de jornalismo \\
\hline 3-) TV Ponta Negra & Rafael Cruz & Gerente de Programação \\
\hline
\end{tabular}

(elaborado pelas autoras com base nas entrevistas já realizadas)

Depois da Colônia e das Redes definidas partiu-se para elaboração do roteiro de entrevista a ser seguido durante as entrevistas, visto que os objetivos delas era compreender como cada emissora passou pelo processo de digitalização do sinal analógico. Partindo de uma pergunta de corte, que de acordo com José Carlos Sebe Bom Meihy deve ser uma questão que perpassa todas as entrevistas e que deve referir à comunidade de destino que marca a identidade do grupo analisado, quase sempre a pergunta de corte vem no final da entrevista. No caso desta pesquisa foi solicitado a cada um dos entrevistados, ao final da entrevista, que fizesse considerações sobre a transmissão do sinal digital para o Rio Grande do Norte. Além disso, foi perguntado também temas como: início do processo de digitalização, sobre projeto para divulgar a mudança; sobre as principais modificações técnicas sofridas ao longo do processo; sobre a necessidade de ajustes na programação durante a mudança; sobre a necessidade de capacitação para a equipe técnica/jornalística; sobre a realização alguma pesquisa para saber se o sinal digital está funcionando; e sobre a questão envolvendo a participação dos telespectadores, a partir do sinal digital.

As primeiras entrevistas gravadas ${ }^{3}$, até o momento, foram transcritas para serem utilizadas como fonte de informação e serão divulgadas por meio de uma publicação para a referência de pesquisadores, estudantes e a sociedade em geral. O processo de transcrição proposto pela história oral não foi desenvolvido porque não se trata de um projeto específico para este fim, e sim uma apropriação da história oral, como ferramenta metodológica de pesquisa, que se utiliza da entrevista, e coloca o

\footnotetext{
${ }^{3}$ As entrevistas foram realizadas pelo bolsista de iniciação científica Rafael Barbosa.
} 
entrevistado na perspectiva de colaborador, "é um termo importante na definição do relacionamento entre o entrevistador e o entrevistado. Sobretudo, é fundamental porque establece uma relação de compromisso entre as partes" (José Carlos Sebe Bom Meihy, 2005: 124).

\section{Resultados}

A partir do instrumental metodológico utilizado nesta pesquisa, com o objetivo de mapear os caminhos que levaram à implantação da televisão digital no Rio Grande do Norte, é possível, com o apoio dos primeiros resultados, observar que o desligamento do sinal analógico, no dia 30 de maio de 2018, na capital do Rio Grande do Norte e grande Natal ocorreu em um clima de tranquilidade. As cinco principais emissoras do Estado, mesmo que tendo passado por momentos de instabilidade na transmissão do sinal, que caracterizou a fase de implantação da televisão digital, conseguiram concretizar o processo no prazo estabelecido pelo Ministério das Comunicações. De forma que não houve casos de comunidades ou indivíduos que ficaram sem o sinal digital. Apesar dos altos índices de pobreza no Estado do Rio Grande do Norte, uma intensa campanha, com a distribuição de equipamento para a adaptação do sinal dos aparelhos analógicos foi desenvolvida. A organização não-governamental Seja Digital (EAD Entidade Administradora da Digitalização de Canais TV e RTV), que é uma empresa sem fins lucrativos, foi responsável por operacionalizar a migração do sinal analógico para o sinal digital da televisão no Brasil. A empresa foi criada por determinação da Anatel (Agência Nacional de Telecomunicações), e tem como missão garantir que a população tenha acesso à TV Digital, oferecendo suporte didático, desenvolvendo campanhas de comunicação e mobilização social, além de distribuir kits para a implantação da TV digital para as famílias cadastradas em programas sociais do Governo Federal. Ainda entre os objetivos, também é necessário aferir a adoção do sinal de TV digital, remanejar os canais nas frequências e garantir a convivência sem interferência dos sinais da TV e 4G após o desligamento do sinal analógico de televisão. De acordo com site da empresa, "Esse processo teve início em abril de 2015 e, de acordo com o cronograma definido pelo Ministério da Ciência, Tecnologia, Inovações e Comunicações, mais de 1300 municípios terão o sinal analógico desligado até $2018^{\prime \prime 4}$.

Por meio das informações apuradas durante as entrevistas com os profissionais e de consultas aos sites das emissoras de Natal foi possível observar, em conformidade com o quadro 3, que as cinco principais emissoras de Natal estão transmitindo o sinal digital, e que o processo começou com a InterTV Cabugi (Globo), em 22 de março de 2010,

\footnotetext{
${ }^{4}$ http://www.sejadigital.com.br/sobre
} 
depois disso, a segunda emissora a passar pelo processo de transição foi a Band Natal (Bandeirantes), no dia 11 de junho de 2010. A terceira emissora a se converter em digital no estado do Rio Grande do Norte foi a TV Ponta Negra (SBT), no dia 25 de junho de 2014, em seguida foi a vez da TVU (TV Brasil), no dia 15 de maio de 2015, e finalmente, a última a digitalizar o seu sinal foi a TV Tropical (Record), no dia 07 de maio de 2018. Esta cronologia demonstra que foram necessários cerca de oito anos para que processo de digitalização fosse completamente implementado nas principais emissoras comerciais da capital e região metropolitana do Rio Grande do Norte. No interior do estado ainda existe a dupla distribuição de sinais, ou seja, atuam com o analógico e o digital, pois o processo ainda está em curso.

\section{Quadro 3 - Cronologia da digitalização em Natal}

\begin{tabular}{|c|c|c|}
\hline ORDEM & EMISSORA & DATA DE DIGITALIZAÇÃO \\
\hline $1 \underline{a}$ & Inter TV Cabugi/globo & 22de março de 2010 \\
\hline $2 \underline{a}$ & band natal/ bandeirantes & 11 de junho de 2010 \\
\hline $3 \underline{a}$ & tv ponta negra/ sbt- 13.1 & 25 de junho de 2014 \\
\hline $4 \underline{a}$ & tvu - ufrn/ tv brasil & 15 de maio de 2015 \\
\hline $5 \underline{a}$ & tv tropical/ record & 07 de maio de 2018 \\
\hline
\end{tabular}

(Elaborado pelas autoras com base nas entrevistas realizadas e em sites das emissoras)

A partir do acompanhamento e a observação do processo de digitalização em Natal, por intermédio do acompanhamento da programação das emissoras e também, a partir das entrevistas realizadas pode-se ter uma dimensão de como se deu a trajetória de digitalização da televisão no Rio Grande do Norte.

Para este artigo, contamos com as impressões de profissionais de três das cinco emissoras pesquisadas, visto que as duas outras entrevistas ainda estão em fase de transcrição no momento do fechamento deste texto.

Na InterTV Cabugi, o processo ocorreu de forma gradual e com uma programação determinada pela emissora de rede (Globo). De acordo com diretor de jornalismo da InterTV Cabugi, na época, o jornalista Luiz Veiga, o processo teve início em novembro de 2010. Segundo ele, foi necessário fazer duas emissoras, durante o período de transição, "uma analógica e outra digital. À medida que o tempo foi passando, foi deixando apenas o digital" (Luiz Veiga, 2018). A mesma programação era exibida em dois canais (analógico e digital). Na parte técnica, houve treinamento com os fabricantes dos equipamentos, e palestras nas praças que iniciaram o processo antes, como Rio de Janeiro e São Paulo. A emissora desenvolveu uma intensa campanha de conscientização voltada para o público, com o objetivo de informar quais as mudanças o sinal digital traria para o telespectador. A respeito da interação que a televisão digital proporciona ao público, o diretor de jornalismo da InterTV Cabugi revela que, 
nós tivemos uma maior participação dos telespectadores. Feedbacks com relação à qualidade, isso aconteceu bastante certo. Realmente com elogios em relação à diferença de qualidade. Mas basicamente esta campanha que houve para o desligamento foi quem fez essa interação maior entre público e televisão (Luiz Veiga, 2018).

Em suas considerações, o diretor de jornalismo da InterTV Cabugi esclareceu que o sinal digital tem uma qualidade superior ao analógico, tanto em relação à imagem quanto ao som. "É uma tecnologia que está em constante desenvolvimento. Ou seja, o que nós temos hoje pode ser que não tenhamos daqui a cinco anos. Seja uma tecnologia deferente" (Luiz Veiga, 2018). Ele ressalta que o processo é irreversível para enfrentar a concorrência com os outros meios. "O primeiro passo foi dado, a gente era obrigado a ter essa melhoria em nosso sinal, frente aos outros meios que também evoluíram: internet, TV por demanda, TV a cabo que também se tornaram digitais".

Para a produtora de jornalismo Diana Barreto (informação verbal, 2018) a transição foi aos poucos, mas houve um marco na produção de telejornalismo, "a gente marcou este momento fez um jornal especial, com uma transmissão ao vivo explicando para os telespectadores como seria essa mudança e principalmente porque seria um momento uma transição". Para ela, além de mais qualidade na imagem, é possível entregar um produto melhor para o telespectador. Durante a transição foi exibida uma série de reportagens para explicar ao telespectador o que é a TV digital. "Porque tem toda uma parte mais burucrática, mais técnica, mas a gente tentou traduzir isso em formato de matéria, e a gente fez uma série de reportagens explicando exatamente o que era o sinal digital" (Diana Barreto, 2018). Para os jornalistas da redação, principalmente os que aparecem no vídeo (repórter e apresentador), a produtora revela que houve algumas mudanças:

Existia uma preocupação dos próprios profissionais em relação à imagem, já que o sinal digital dá um detalhe maior, um detalhe melhor. Então até com relação à maquiagem, à iluminação, à roupa. Tudo isso teve uma preocupação e uma adaptação para o sinal digital (Diana Barreto, 2018).

Para Barreto (2018) houve uma aproximação da equipe de jornalismo com o telespectador,

porque a pessoa começa a perceber que aquele sinal é um sinal de qualidade, é um produto de qualidade que a gente entrega pro telespectador [...] e as pessoas gostam realmente de ter essa qualidade em casa e se sente mais próximo até do profissional, mais perto do apresentador. Você consegue ver aquilo com mais nitidez. E isso agrega pra gente e agrega para o telespectador (Diana Barreto, 2018). 
O chefe de reportagem da InterTV Cabugi, Filipo Cunha (2018) revelou, que a primeira transmissão digital, em Natal, aconteceu no ano de 2014. Na Copa do Mundo, onde as duas emissoras que tinham o direito de transmissão eram a Globo e a Bandeirantes, "de forma aberta e gratuita foi na Copa do Mundo da Africa do Sul. Então é alí que começa, um pouquinho antes, os preparativos de digitalização, mas o impacto no ar foi na Copa de 2014, o primeiro grande evento transmitido por TV digital, em sinal aberto" (Filipo Cunha, 2018). De acordo com ele, houve um processo operacional na parte da engenharia da emissora, "a transformação do sinal digital implica em algumas coisas técnicas e operacionais, muito mais voltadas na parte da engenharia do que da parte do jornalismo" (Filipo Cunha, 2018). Na parte do jornalismo existem algumas preocupações, como por exemplo, a TV passa a ser exibida no formato 16X9, que fica naquele tamanho mais largo do que o tradicional 4X3 quadrado. "Isso implicou em o repórter poder ficar longe pra fazer uma entrevista, se não ele aparecia muito mais no quadro do que antigamente. Então estas adaptações dentro do jornalismo foram mais simples" (Filipo Cunha, 2018). Esta mudança no formato do quadro ampliou o campo de cobertura da câmera, "o editor consegue ver muito mais coisas na TV, a imagem é muito mais ampla. Então muda um pouquinho para o cinegrafista, para o repórter cinematográfico" (Filipo Cunha, 2018). Para ele, não muda o conteúdo, mas muda como chega este conteúdo. "Esse pacote visual, ele muda. Então os editores tiveram imagens melhores para trabalhar, porém com a imagem precisava de maior atenção. Os repórteres também, mais qualidade na imagem, mas também tem que se cuidar mais" (Flipo Cunha, 2018).

Na TV Ponta Negra, o processo de digitalização iniciou em 2014, quando a emissora foi vendida para o grupo Hapvida. De acordo com o gerente de programação da emissora, Rafael Cruz, o primeiro passo foi "a compra do transmissor digital e gerada a imagem digital. Sendo que antes já havia também uma compra de equipamentos, como câmera" (Rafael Cruz, 2018). Depois disso, várias outras atividades e campanhas se desenvolveram, como a campanha institucional da emissora, conforme imagem 1 abaixo, que mostra por meio de um vídeo disponível no canal do YouTube da emissora, com as principais características e qualidades da televisão digital. Além disso, uma série de reportagens, em parceria com a ONG Seja Digital, com o acompanhamento de seu trabalho nos bairros da periferia da cidade, distribuindo o kit para TVs analógicas poderem receber o sinal digital, "foi uma informação muito maciça, muito presente. Tanto é que Natal cumpriu o prazo. Dentro do previsto foi desligado o sinal analógico porque cumpriu aquela meta de 93\% dos lares com acesso ao sinal digital" (Rafael Cruz, 2018). 


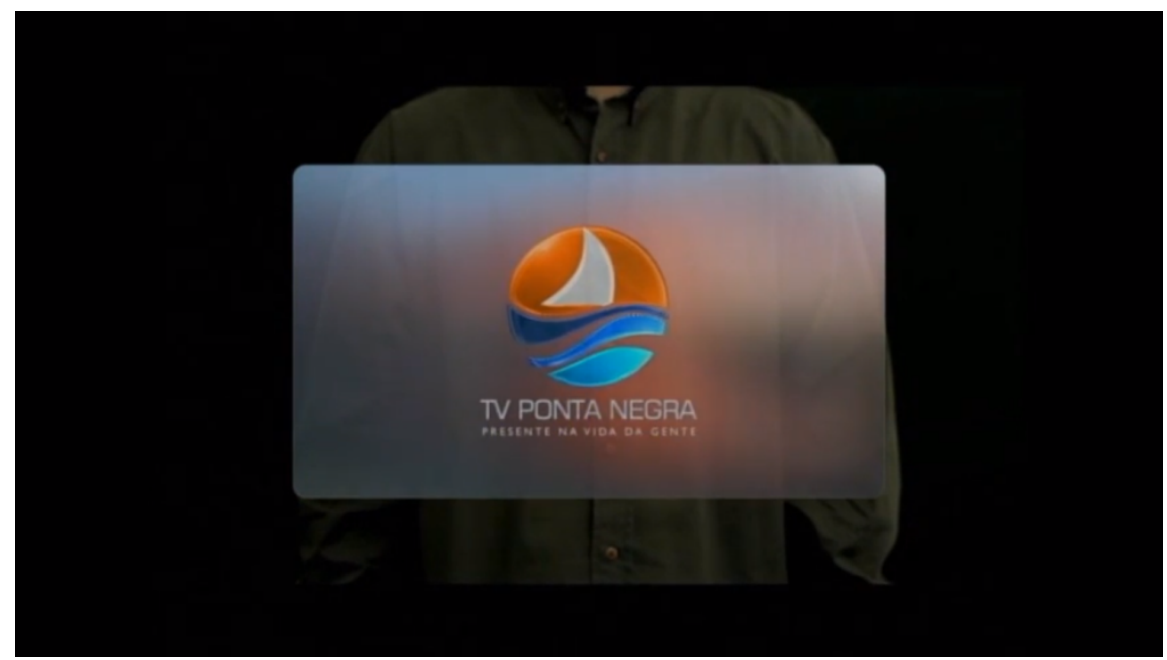

Fonte: www.youtube.com/watch?v=-Bby1u3ILU8

De acordo com ele, a mudança só pode ser observada em sua íntegra a partir de 2018, com o desligamento do sinal analógico, "houve uma transformação profunda porque a gente teve que trocar as câmeras, as câmeras de estúdio. É uma outra iluminação" (Rafael Cruz, 2018). Além disso, os espaços físicos da emissora tiveram que ser readaptados. "Os cenários foram refeitos e tiveram que ser repensados, já na apuração do HD que pega os detalhes como a profundidade, o relevo" (Rafael Cruz, 2018). Na parte técnica houve um processo intenso, que alterou o dia a dia da empresa. "As nossas ilhas de edição tiveram que passar por upgrade porque o material em HD demanda mais memória, demanda mais tempo pra transferir um arquivo para o exibidor" (Rafael Cruz, 2018). Para realizar todo o processo, a equipe de engenharia da emissora inicialmente estudou as posibilidades e em seguida fez um cronograma por etapas. Na primeira etapa, a emissora começou a transmitir no estúdio em HD. Numa segunda etapa, passou a transmitir também as matérias, "não foi feito tudo de uma vez não. Isso contribuiu para que a gente pudesse absorver todas estas mudanças" (Rafael Cruz, 2018). As mudanças mexeram com a rotina de produção da redação de jornalismo. "Principalmente nessa coisa da velocidade da informação que hoje a gente concorre não só com TVs concorrentes, com a própria internet, com outros veículos" (Rafael Cruz, 2018). No departamento de jornalismo, o processo de informação e capacitação dos profissionais começou em 2010. "Nós não estávamos nem ainda operando em sinal digital, mas naquela época, nós tivemos um treinamento de jornalismo, com a vinda de uma pessoa do SBT pra falar um pouco de figurino, de maquiagem, do que iria mudar com a chegada do digital" (Rafael Cruz, 2018). Outras discussões seguiram sobre os mais variados temas que se relacionam com a televisão digital, como um novo modelo de negócio, e as possibilidades de interatividade. Em 2018 o grupo Opinião, do qual a TV Ponta Negra faz parte, reuniu todas as emissoras do sistema para discutir questões relacionadas ao conteúdo digital. "Nem tanto mais a parte técnica que está aí, mas a parte do conteúdo e dos novos modelos de negócio" (Rafael Cruz, 2018). 
Em relação ao orçamento e aos custos de todo o processo de digitalização da TV Ponta Negra, Rafael Cruz revela que a empresa seguramente já investiu cerca de quatro milhões de reais. De modo que em 2018 foram gastos um milhão e meio, com a troca da mesa de corte, câmeras de estúdio e de externa, cabeamento, entre outros equipamentos. "Fora o nosso transmissor que também custa nesta faixa de um milhão e meio de reais" (Rafael Cruz, 2018). Agora, o desafio da TV digital é estar $100 \%$ no interior do estado também. "Existe um processo de expansão, de interiorização, que vai ser executado no próximo ano. A região Seridó precisa do nosso sinal digital, o mais extremo oeste alí do Estado, na tromba do elefante" (Rafael Cruz, 2018).

Na TVU, que foi a primeira emissora do estado, o sinal digital começou a ser transmitido a partir do dia 15 de maio de 2015, mas o processo de migração do sinal analógico para o digital começou por volta de 2010, quando foi aprovado o projeto de financiamento do transmisor digital, "que envolvia várias áreas de conhecimento da universidade, vários professores, e que inclusive financiou um processo de elaboração de novas linguagens em TV digital" (Iano Maia, 2018). Segundo lano Maia (2018) foi um projeto chamado XPA Lab. "Esse projeto que foi financiado pelo CTINFA, que é um edital nacional. Ele começou a ser executado em 2011. Esse projeto viabilizou a compra do transmissor digital" (Iano Maia, 2018).

Com o início das transmissões digitais, a TVU ficou em fase experimental, mas depois teve problemas técnicos, o que deixou a emissora seis meses fora do ar. O sinal digital foi restabelecido no dia 31 de maio de 2018. O projeto institucional desenvolvido pela TVU era só uma das etapas - a de transmissão digital. "Todo o outro processo de transição digital nunca foi executado. A gente tá agora começando a se preparar pra isso, mas todo o nosso parque de equipamento está obsoleto" (lano Maia, 2018). O processo de mudança na produção de conteúdo continua analógico, apesar de a transmissão ser digital, "não melhorou qualidade de imagem, a gente não mudou formato de programa, a gente não mudou nada no estúdio, e nada nas externas" (lano Maia, 2018). Em 2018 iniciou-se a produção de conteúdo em alta definição, mas não para ser exibido na televisão, e sim para ser usado na internet. Este fato revela, que mesmo já tendo sido desligado o sinal analógico, e com a transmissão digital, a produção de conteúdo da emissora continua analógica. Mesmo com um investimento de cerca de um milhão e meio de reais, feito pela Finepe para a implantação do transmissor digital, a TVU continua produzindo conteúdo analógico e ainda tem um longo caminho até chegar completamente à era digital. 


\section{Discussões e considerações finais}

Com o objetivo de mapear a trajetória de implantação da televisão digital do Rio Grande do Norte, este artigo buscou apresentar uma parte dos resultados obtidos até o momento. Com a amostra, adquirida a partir de entrevistas realizadas com profissionais de três emissoras foi possível considerar que o processo, na sua plenitude, ainda está em andamento, mas muito ainda deve ser feito. Mesmo que o sinal analógico tenha sido desligado em maio de 2018, uma das emissoras (TVU) continua produzindo conteúdo analógico e transmitindo em digital, dessa forma, o produto que chega para o telespectador ainda é de baixa qualidade e por isso a experiência do telespectador fica prejudicada.

Outro dado importante é em relação aos investimentos realizados para a migração do sinal analógico para o digital, no qual duas emissoras fizeram aproximações a respeito dos valores gastos no processo, mas uma delas optou por omitir os valores, e por isso fica difícil ter uma real dimensão do esforço que foi despendido para que o processo de digitalização fosse concretizado, além de demonstrar um receio por meio da emissora de apresentar os dados de maneira clara e objetiva. O que de maneira geral dificultou nossa análise, uma vez que uma das etapas que perpassa o processo de digitalização da televisão são os investimentos financeiros das emissoras para que a conversão seja feita de maneira eficaz e completa.

Por se tratar de um processo radical de mudança, observou-se o período entre o início e o término da migração do sinal analógico para o digital, são necessários de 4 a 5 anos de planejamento, desenvolvimento e efetivação propriamente dita da mudança. Isso porque durante boa parte deste processo funcionam simultaneamente duas emissoras, sendo uma delas com sinal analógico e outra com sinal digital. Em alguns casos a mudança vai sendo realizada por etapas, já que não é possível realizar tudo de uma só vez, devido ao alto custo de investimento em tecnologia e treinamento dos profissionais. Este artigo tentou demonstrar a complexidade deste processo e como o planejamento ou a falta dele pode resultar em uma dificuldade de implementação do sinal digital, como observamos na TV Universitária.

Quanto aos benefícios gerados pelo sinal digital, destacam-se a melhoria na qualidade da imagem em formato retangular (16X9), em substituição ao anterior quadrado (4X3), e do som, com substancial melhoria na qualidade de recepção do sinal, com eliminação de chuviscos e perdas de sinal. Além dos benefícios já citados, pode-se identificar por parte das equipes de produção de jornalismo um aumento na participação do telespectador, devido ao que Jenkins (2009) denominou de convergência. Comprovouse a ligação existente entre o termo (convergência) e o processo de digitalização da televisão, porque ele define as mudanças tecnológicas, industriais, culturais e sociais relativas às novas maneiras como as mídias circulam na cultura, e que abre posibilidades 
para novos modelos de negócios, conforme foi observado nas entrevistas realizadas ao longo da pesquisa.

Além dos benefícios técnicos, observamos que o processo de digitalização envolve mais que somente as emissoras, a comunidade deve estar preparada para receber o sinal digital, entender a importância de ter televisores e conversores que tornam possível a recepção do sinal digital em todas as residências. Por isso, o papel da ONG Seja Digital foi de extrema importância para democratizar o acesso à parte da população de baixa renda e que não teria como arcar com os custos de novos aparelhos televisivos ou de conversores digitais. Em um país como o Brasil, onde a desigualdade é o grande vilão, iniciativas de democratização ao acesso à televisão digital são sempre necessárias, já que a televisão está presente em $97 \%{ }^{5}$ dos lares brasileiros e é, ainda hoje, a mídia mais vista no Brasil.

Por fim, a utilização de alguns preceitos da história oral, por meio da fomação de uma colônia e de redes de entrevistados como parte da metodologia possibilitou uma aproximação com profissionais identificados nas emissoras, o que nos permitiu contar uma parte da trajetória de digitalização da televisão no Rio Grande do Norte e dar mais um passo em direção à memória e resgate da história da televisão local. Lembrando que este é só o primeiro passo da caminhada em busca de compreender os processos que levaram à digitalização da televisão no Rio Grande do Norte. Esperamos ao fim da pesquisa ter um panorama geral das ações realizadas, das dificuldades enfrentadas, erros e acertos ao longo do desenvolvimento da digitalização, para desta maneira poder escrever mais um capítulo da história da televisão potiguar e, assim, compreender a evolução do meio televisivo em um panorama local e como ele se relaciona com as mudanças que estão ocorrendo em todo o mundo.

\section{Referencias bibliográficas}

ASSMANN, A. (2011). Espaços da recordação - formas e transformações da memória cultural. Campinas: Unicamp.

BARRETO, D. (2018) Chefe de Reportagem. Entrevistado em Natal durante a realização da pesquisa; Inter TV Cabugi.

BOURDIEU, P. (1997). Sobre a Televisão. Rio de Janeiro: Zahar.

\footnotetext{
${ }^{5}$ http://agenciabrasil.ebc.com.br/economia/noticia/2018-02/uso-de-celular-e-acesso-internet-saotendencias-crescentes-no-brasil
} 
CANNITO, N. (2010). A televisão na era digital. São Paulo: Summus.

CUNHA, F. (2018). Chefe de Reportagem. Entrevistado em Natal durante a realização da pesquisa; Inter TV Cabugi, 2018.

CRUZ, R. (2018) Gerente de Programação. Entrevistado em Natal durante a realização da pesquisa; TV Ponta Negra.

DIGITA. S. (2018). Disponível em: http://www.sejadigital.com.br/sobre Acesso em 05 de maio de 2019.

DUARTE, J. ; BARROS, A. (2005). Métodos e Técnicas de Pesquisa em Comunicação. São Paulo: Editora Atlas.

FREITAS, S. M. de. (2006). História Oral: procedimentos e possibilidades. São Paulo: ebook.

GAGNEBIN, J. M.(2005). Sete aulas sobre linguagem, memória e história. Rio de Janeiro: Imago.

KNEIPP, V. A. P. (2017). Trajetória da televisão no Rio Grande do Norte: a fase analógica. Natal: EDUFRN. Recuperado em 22 de abril de 2019, https://repositorio.ufrn.br/jspui/bitstream/123456789/24528/1/Trajetoria_da_T $\underline{\mathrm{V} \text { no } R N \text { a fase analogica.pdf. }}$

LOPES, M. I. V. de. (1994). Pesquisa em Comunicação Formulação de um modelo metodológico. São Paulo: Loyola.

MACHADO, A. (2000). A televisão levada a serio. São Paulo: Senac.

MAIA, I. (2018). Chefia de Jornalismo. Entrevistado em Natal durante a realização da pesquisa; TVU.

MATTOS, S. A. S. (2002). História da televisão brasileira - uma visão econômica social e política. São Paulo: Vozes.

MAUAD, A. M. (2016). História oral e mídia. São Paulo: Letra e Voz,.

MEIHY, J. C. S. B. (2005). Manual de História Oral. São Paulo: Edições Loyola.

THIOLLENT, M. J. M. (1980). Crítica metodológica, investigação social \& enquête operária. Polis.

VEIGA, L. (2018). Diretor de Jornalismo. Entrevistado em Natal durante a realização da pesquisa; Inter TV Cabugi. 